\title{
Prevalence of Childhood Depression: The Effects of Teacher-Students Relationship as Predictor Factors to Depressive Symptoms
}

\author{
Adel Tannous ${ }^{1}$ \\ ${ }^{1}$ School of Educational Sciences, University of Jordan, Jordan, Amman, Jordan \\ Correspondence: School of Educational Sciences, University of Jordan, Jordan, Amman, Jordan. E-mail: \\ a.tannous@ju.edu.jo
}

Received: January 11, 2017

Accepted: November 22, 2017 Online Published: December 18, 2017

doi:10.5539/mas.v12n1p9

URL: https://doi.org/10.5539/mas.v12n1p9

\begin{abstract}
The aims of this study are to determine the prevalence of depression among children, and scrutinize the teacher-student relationship as predictor factor to depressive symptoms according to the children's perception. The Jordanian translation of Children's Depression Inventory (CDI) was used in this study. The study was carried out among children in private and state schools within the age range of (7-13) in Amman city. The sample on which the study tools were applied consisted of 705 children. The results of this study indicate that the prevalence of moderate depression was the lowest (3.8\%) at the age of 8 and the highest (5.8\%) at the age of 11 . The prevalence of severe depression was lowest $(2.3 \%)$ at the age of 9 and highest $(6.8 \%)$ at the age of 13 . The results also show that there is no single cause of depression and it is difficult to separate the different causes. All the children with severe depression discuss how the teacher-student relationship as predictor factors to depressive symptoms. From the analysis of the results, specific reasons to teacher-student relationships that cause depressive symptoms are categorised into two basic factors these are: The teacher-student interaction, and peer influence.
\end{abstract}

Keywords: depression, children, relationship, teacher, student

\section{Introduction}

Research into the nature and characteristics of depression in adults (Miller, 1998; Kendall, 2000; Nelson, 2001; Herman \&Ostrander 2007; Saqib, 2014; Yap \& Jorm, 2015; Wang et al., 2015) has provided an important framework for much of the recent investigations into childhood depression. Depression was seen as an adult disorder, children were considered too developmentally immature to experience depression, and adolescent low mood was seen as part of normal teenage mood swings. Developmental studies have been central in modifying that view. Few would now doubt the reality of child and adolescent depressive disorder, or that children depression is associated with a range of adverse outcomes including social and educational impairments as well as both physical and mental health problems later in life (Thapar, et.al, 2012).

The prevalence rate of depression among adult range from 10-17. Earlier in development prevalence rates in childhood depression are low with no gender differences and then increase significantly in adolescence, while gender differences emerge (Costello et al., 2003). Bilaç and his colleagues (2014) revealed that the prevalence rate of depression in elementary school students in Turkey is $2.6 \%$ and it is approximately two times more common in girls than boys

Research also shows that around $10-15 \%$ of the child present significant depressive symptoms (Hammen \& Rudolph, 1996; Liu et al., 1999), whilst other studies report figures of 23.6\% (Steinhausen \& Winkler, 2003), or even $25.2 \%$. While prevalence rates differ depending on the methodology employed (sample, instruments, informants, etc.), the truth is that childhood depression is one of the most undertreated and debilitating psychological disorders (Cicchetti \&Toth, 1998).

According to DeFilippis and Wanger (2014) girls are twice as likely to be identified as depressed as boys, and prevalence increased with age (8\% in 13-14 years old and 15\% in 17-18 year olds). Differences in psycho-social pressures and styles between girls and boys may play a more important role. But studies carried out in clinical settings reported higher prevalence rates and different distribution rates between genders. Berton and his colleagues (2012) pointed out that 6-11 aged children diagnosed with depression were $4.6 \%$ of all admissions 
and boys are four times more common than that of girls.

WHO reports have identified depression as the second cause of illness among the population aged 15 to 44 in both sexes (WHO, 2011). These figures suggest that depression actually starts earlier than was thought, making it especially important to study depression among children.

According to Aktepe and his colleagues (2010) children and adolescents are frequently referred to psychiatry clinics on account of their externalizing behavior problems such as irritability, inattention or hyperactivity and it is arguably claimed that behavioral problems may well hide the depressive symptoms in childhood. In addition, studies reflect a strong relationship between the age of child and the appearance of depressive symptoms, but it could be difficult to notice and correctly diagnose, due to the various clinical impressions of depression (Allgaier et al., 2014). To put it differently, an infant, may represent somatic symptoms such as loss of appetite or sleep problems as sadness, a pre-schooler might well show irritability or separation anxiety or an adolescence could reveal similar depressive symptoms alike with adults (Mehler-Wex and Kölch, 2008; Williams et al., 2005). In school-aged children, externalizing behaviors including irritability, low frustration tolerance and temper tantrums may easily be manifested as symptoms of depression (Birmaher and Brent, 2007). This complex symptomatology highlights that children who admitted to clinics, even due to their externalizing behavior problems, should also be evaluated in terms of internalizing behavior problems such as depression.

Reviewing related literature of depression among children, there are at least two major symptoms. These symptoms are feeling of sadness or irritable mood and low motivation or lose of interest in most daily living events or activities (Haugaard, 2008; Kaye, \& Munson, 2002).The Diagnostic and statistical Manual of Mental Disorders, 5th edition (DSM-5) criteria for major depressive disorder include a 2-week period where five of the following symptoms are present most of the day, nearly every day: depressed mood (may be an irritable mood in children), loss of interest or pleasure, increased or decreased appetite, insomnia or hypersomnia, psychomotor retardation, loss of energy, excessive guilt, decreased concentration, and suicidal thoughts. At least one of the symptoms must be either depressed/ irritable mood or loss of interest. The symptoms must cause significant distress or impairment in functioning. Depression affects children's quality of life and is a risk factor for poor academic achievement, substance abuse, anxiety, suicidal behaviour, whereas in the long-term they can affect social, cognitive, behavioural, academic and emotional development of the child, becoming an important predictor of psychopathologies in adulthood (Lima et al., 2013, Frojd et al., 2008). Even a moderate depression can leave a child feeling hopeless and helpless enough to be suicidal (American Academy of paediatrics, 2000). In general, depression means downturn in mood status of the person which is differentiated from clinical depression that negatively affected daily life activities (Sarason, 2007). Because of varying factors which include; family factors, genetic factors, and psychosocial factors, the clinical picture of depression differ from person to another (Nevid, \& Greene 2006).

For school-aged children, the school environment or climate should be a central focus of assessment and intervention (Greenberg, \& Bumbarger, 2001). In a national study of schools and children's mental health. Knitzer, and Fleisch (1991) noted that altering the school climate itself is a psychological intervention and school personnel are vital in how the climate is fostered.

According to Reynolds \& Kamphaus (2004) school adjustment such as school performance, adaptation of behaviour to the school, negative attitude toward teachers, and negative attitude toward the school play an important role to develop depressive symptoms. Previous studies have found that teachers considered children with depression showed poor adjustment that is, they worked and learned less, their academic performance was lower and they tended to need special classes, with no differences according to gender.

Some studies have focused on school climate from the student perspective, identifying factors such as students' perceived achievement motivations; perceptions of fairness, order, and discipline; as well as other perceived institutional and organizational structures (Khoury-Kassabri, Benbenishty, \& Avi 2005; Kuperminc, \& Blatt, 2001; Loukas, \& Horton, 2004; Roeser, et al., 2001). Other studies have focused on the perspectives of teachers, administrators, and other school personnel (Bruns, et al., 2004).

Although there is a growing literature regarding the role of school climate in externalizing behaviors, only a few studies have focused on its impact on internalizing problems like depression. Loukas \& Robinson (2004) indicated that higher perceptions of competition and lower perceived cohesion were associated with an increase in boys' internalizing problems, whereas higher internalizing problems for girls were associated with lower perceived satisfaction with classes.

According to Kasen and his colleagues (1990) Schools with high levels of conflict and social facilitation were associated with increased psychopathology among students, this study indicate that student perceptions of their 
school environment are associated with their emotional well-being.

Therefore, it is important to explore the question of whether the information provided by children about their depressive feelings coincides with that provided by parents or teachers. Loeber, and his colleagues (1990) indicate that teachers tend not to detect students with depressive feelings, the children themselves or their mothers being better informants. Woo and his colleagues (2007) found greater prevalence of depressive symptoms on using self-reports than on using teachers' reports. In the same line, other studies have found positive but quite low correlations between teachers' reports and children's self -reports.

Taking into account all of this research, it is clear that the school context is one of great relevance for the detection and prevention of child depression, given that if this problem is not detected in time, the depressive symptoms can become consolidated and chronic in subsequent developmental.

Thus, the present work emerges from an interest in spreading knowledge about childhood depression to schools, with a view to helping teachers identify prevalence and causes of depressive symptoms in school sittings. Therefore, this study is conducted under the general theme elementary students' perception of their relation with teachers as predicting factors to depressive symptoms. The overall purpose is to securitize the situation of children with depression at school from their own perspectives. Furthermore, the study has specific aim to get answer to the following questions: what are the prevalence rate of depression symptoms and what are the school factors that may cause depression among children according to the children's perception?

\section{Methodology}

\subsection{Children's Depression Inventory}

The Children's Depression Inventory (CDI; Kovacs, 1992) was translated into the Arabic language with the purpose to gain a representative picture of the validity of the CDI. This translation came through different stages:

\section{Translation}

The present researcher in collaboration with another independent expert in the field produced two separate translations of the Children's Depression Inventory into the Arabic language in order to detect errors and divergent interpretations of ambiguous items in the original copy of the CDI.

\section{Back translation}

Back translation was applied in this study, in order to avoid major deviations in meaning between the original English version developed by Kovacs (1992) and the Arabic version. Therefore, the two copies of the Arabic translation of the inventory were given to two psychiatrists with wide experience, to make back translation from the Arabic language into the English language. Each psychiatrist is given one copy of each of the Arabic translation.

\section{Committee reviews}

The researcher in collaboration with three experts in the field reviewed the final version of the Arabic copy of the CDI. To ensure that the translation is fully comprehensive a review was made to the instructions of the inventory as well as the scale of responses to each item. After that, the committee proposed a few amendments on the final version.

\section{Exploratory study}

An exploratory study was made on a group consisting of 178 boys and girls between the age 7 and 13 years from state and private schools. In order to check the errors and deviations in the translation, and also to make sure of the clarity of the items, suitability of the terms and answering instructions for the age group of the children. And last but not the least, the comparison between this translation and the Ghisan (1994) translation indicated that there are no differences between the two translations. In view of the foregoing, the present researcher was content with the Children's Depression Inventory validity and considered it appropriate to use for research purposes.

The Jordanian Translation of the Children's Depression Inventory (CDI) is used in this study. It includes 27 items that assess affective, cognitive and behavioural symptoms of depression, no item excluded. The children filled in a 27-item questionnaire during a school lesson. The researcher had read the items to the children in the classroom. For each item, the child is asked to endorse the one of the three statement that best applies to him or herself during the last two weeks. For example, for one of the items, a child is asked to select one of each set of these alternatives: (a) I am sad once in a while (b) I am sad many times (c) I am sad all of the time. The child's score on the Children's Depression Inventory $(0,1$ or 2$)$ is based on the more is based on the more extreme 
statement that is endorsed in the direction of depression and the theoretical total score can range from 0 to 54 . Scores on the inventory can be divided as follows: (0-11) Non-depressed, (12-18) Moderate depression, and (19 and above) Severe depression.

A cut off score of 19 has been suggested as a criterion level for defining clinical levels of depression based on initial scale development and normative studies of the CDI (Kazdin, 1989; Kovacs, 1992). However, depressed children were defined as children with a self-report CDI score of 19. Kovacs (1992) reported that a cut off score of 19 on the CDI identified children in the upper $10 \%$ of the distribution in a sample of non-clinic children. Doefler et al., (1988) also reported that a cut off score of 19 on the CDI, identified $10 \%$ of the children as depressed.

\subsection{Participants of the Study}

Participants in the present study are the children in private and state schools within the age range of (7-13) years in elementary schools who were randomly selected in Amman city. The children were chosen for the study sample from 26 schools (11 state \&15 private schools) in proportions representative of their residence in different living environments (city, semi-rural and rural areas).

The original sample on which the study tools were applied consisted of 765 children. After reviewing the answering questionnaires it was found that 60 children's questionnaires were excluded (7.8\%) because children had not answered most of the questions. Therefore, the sample of the present study consisted of 705 children.

Table 1. Distribution the sample of the study

\begin{tabular}{lllll}
\hline Gender & State school & Private school & Drop out $(\%)$ & Total \\
\hline Girls & 221 & 185 & $23(5.6 \%)$ & 383 \\
\hline Boys & 198 & 161 & $37(10.3 \%)$ & 322 \\
\hline Total & 419 & 346 & $60(7.8 \%)$ & 705 \\
\hline
\end{tabular}

\section{Results}

\subsection{Prevalence of Depression}

The result of children scores on the (CDI) indicates that by using a cut-off score of (12 to 18) 36 children with prevalence rate of $5.1 \%$ forms a group with a possible moderate depression. By using recommended a cut-off score of 19 or more 34 children with a prevalence rate of $4.8 \%$ forms a group with severe depression as shown in the following table.

Table 2. The scores of the children on the Children Depression Inventory (CDI)

\begin{tabular}{lllll}
\hline Age & $\begin{array}{l}\text { Mild Depression } \\
(\mathbf{0 - 1 1})\end{array}$ & Moderate Depression ( 12-18) \% & Severe Depression (19 or more) \% & Sum \\
\hline $\mathbf{7}$ & $24(96 \%)$ & $1(4 \%)$ & 0 & 25 \\
$\mathbf{8}$ & $27(96.2 \%)$ & $1(3.8 \%)$ & 0 & 28 \\
$\mathbf{9}$ & $44(93.3 \%)$ & $2(4.4 \%)$ & $1(2.3 \%)$ & 47 \\
$\mathbf{1 0}$ & $99(91 \%)$ & $5(5 \%)$ & $4(4 \%)$ & 108 \\
$\mathbf{1 1}$ & $165(88.9 \%)$ & $11(5.8 \%)$ & $10(5.3 \%)$ & 186 \\
$\mathbf{1 2}$ & $172(89.1 \%)$ & $10(5.2 \%)$ & $11(5.7 \%)$ & 93 \\
$\mathbf{1 3}$ & $63(88.2 \%)$ & $6(5 \%)$ & $8(6.8 \%)$ & 75 \\
Sum & $635(90.1 \%)$ & $36(5.1 \%)$ & $34(4.8 \%)$ & 118 \\
\hline
\end{tabular}

As shown in table 2 the result of the study indicated that severe depression is non-existent before the age of 8 years. The prevalence rate of moderate depression was lowest (3.8\%) at the age of 8 and highest at $(5.8 \%)$ the age of 11 . The prevalence of severe depression was lowest (2.3\%) at the age of 9 and highest at (6.8\%) at the age of 13 .

The results of this study showed that there are no significant differences between boys and girls in the prevalence rate of severe depression. Girls rated higher than boys in prevalence rate, but these differences are not significant as shown in table 3 . 
Table 3. The scores of the children on the Children Depression Inventory (CDI)

\begin{tabular}{llllllllll}
\hline \multirow{2}{*}{ Prevalence rate of severe depression } & \multicolumn{4}{c}{ Sex } & \multicolumn{4}{c}{ School } \\
\cline { 2 - 11 } Percent & Girls & Boys & df & Sig & Private & State & df & Sig \\
\hline
\end{tabular}

As can be seen in table 3 there are significant differences between type of schools, state schools show higher percent of prevalence of depression than private, and these differences are significant

\subsection{Causes of Depression}

All the children with severe depression discuss how the teacher-student relationship as predictor factors to depressive symptoms. From the analysis of the results, specific reasons to teacher-student relationships that cause depressive symptoms are categorised into three basic factors these are: The role of the teachers and the teacher-student interaction, and peer influence.

\subsubsection{Teacher-Student Interaction}

Through describing the way that teachers treat them the students. Students illustrated their relationship with their teachers in class especially the methods of discipline, many discipline methods were described by students including slapping them in the face, beating them with a stick, assure discipline in class or school. Pull their hair to impose order

Our teacher always slaps us in the face if we do something wrong or if we do not do our homework. She also uses a stick for beating us.

I hate our teachers in all the subjects, because they always scare us in the school.

A teacher once pulled my hair in front of all the students because I wasn't wearing the school uniform.

Teachers deal with us as criminals not students was the opinion of one students expressing their disappointment in teachers' discipline

A teacher asks students who violate the rules or who don't do their homework to stand in front of all the students on one foot. Sometimes it lasts more than 15 minutes. If the student gets tired and puts down his foot the teacher asks him to stand up once again on one foot. It's happened several times to me.

When a student talks during class, the teacher kicks him out of the class. It happened to me. Then we are sent to the principle, who sometimes is busy, and so we remain standing for a whole session (45 minutes) and maybe two sessions in front of the principal's office. When we get a chance to see the principle he asks us to go back to the class or go to the counsellor.

Leaving school and desire for revenge from teachers from was the reaction of one female and one male respectively to the teacher's humiliation and treatment. She wanted to get rid of teachers' mockery and he wanted to revenge of what the teacher who derides him in front of other students

Lots of times I pretend that I'm sick in order not to go to school. I hate school and I specifically hate the math teacher because she derides, talks scornfully to me in front of my classmates

I don't know what to do with the social science teacher, he's violent, he always humiliates me in front of my classmates telling me that I'm stupid and that I don't understand and the best thing for me to do is to leave school and look for a job rather than wasting my time at school, that way I would save my folk's money

When I ask the math teacher to repeat a point again, she comments in front of all the students that there's no problem in not understanding the first time but no matter how many times she explains the point I'll never understand

Mockery and lack of respect is what the teachers attitude toward students is build on

Frankly, I really don't know why they treat us that way. I sometimes feel that they only want to terrify us. It's as if we go to school to be harassed not to learn.

Some teachers treat us in a good way and we feel that they like us, but we hate school because of some other teachers and their offensive way in treating us 
The student feel sad when teachers discipline them in front of others, and this practice arise feelings of embarrassment and insult in the student feeling. Furthermore they feel sad because they face difficulties at home too. But the great effect and influence of sadness of feeling related to teachers discipline methods

Another factor in the teacher practice is students discrimination, which create a feeling of jealousy between the students because of the not equal treatment which include good and distinctive treating

I once talked to my friend during the class, and the teacher sent me to the administration, and my mom had to come to the school. But another student did the same thing and the teacher only talked to her and asked her to pay attention to the lesson and not do it again

During class participation, when the teacher's favourite student answers correctly the teacher asks us to applaud. He starts flattering him in front of us, but when other students do the same thing there's no encouragement

Teachers' discrimination affect both the psychological and the educational level of the students it also the cause of class disorder. Teachers give freedom and Over-spoiling to some students of high academic achievement to do whatever they desire in the class effect the concentration and comprehending ability of the other students in the class

One can't concentrate or understand during class because some students that have high grades speak out and laugh continuously. When we complain to the teacher he asks us to ignore them because they understand the lesson so we're supposed to let them do whatever they want. How on earth does the teacher expect us to learn?

The real reason for discrimination -although not a convincing one- is the teachers' personal interests with the parents. When the father is an important person the teacher pays more attention to his children, because of the economic, political and social status of the parents. The teacher may hope to be appointed as a private teacher for that student or to be able to ask for a personal favour such as providing a job opportunity for a relative.

There's a student in class, whose father is an important person. He is not a good student, because he usually hits the boys at school. No teacher can stop him, and even the principle avoids him. When it comes to any other student or me the teacher always sends us to the principle for discipline. Teachers think we're still young and don't understand why they treat some students perfectly. Frankly, I understand everything but I don't want to speak out. Every teacher has a personal interest and they take advantage of students.

Some students point out the reluctance among teachers, who are capable of providing assistance but they avoid giving a chance to talk about it. Teachers are busy with teaching, and they do not have for private problems time because the school counsellor is there for help. One student says this reluctance extends to complete rejection in the whole educational situation.

I have tried several times to talk about my problem with my favourite teacher but unfortunately she refused to listen

A teacher once told me: if you have a psychological problem let your folks help you out. School is not a psychological clinic

Negative expectations towards students sometimes determine the relationship between the student and teacher. Some teachers' form an impression of the student based on a single situation and this impression determines the way the teacher treats the student. Even when the impression is wrong, the teacher does not give the student the chance to change or improve the image. Therefore, the student's grades may be affected by this attitude.

I don't know how to change the teacher's impression from the first day at school; he thinks I'm careless and not serious. I've tried many times but it's no use. He's completely convinced. It does not matter whether I study or not, everything will remain the same.

An impression formed by one teacher is passed on to other teachers, considered as an advice given to new teachers to guide them how they should treat students and not be fooled by lies and tricks. This situation creates aggressive reactions among the teachers who try to avoid those students.

The first thing that our new math teacher told me when he first knew my name was: "Is that you, I've heard a lot about you". I didn't understand what he really meant but soon he started treating me the same way other teachers treat me. Now I understand what he meant

One of the teachers used to like me and treated me well. After a while I noticed that she had changed her way in dealing with me without any reasonable cause. I tried many times to ask her why she has been 
avoiding me, but even now I don't know the reason of the sudden change in treating me. It's probably the impression that other teachers have of me

The feelings of sadness are reactions of negative expectations. Students feel frustrated when they make continuous attempts to change impressions, which are unfair. Teachers must check all information because its effect extends into the educational and psychological process.

We used to have a teacher, who had been in our school for many years. She always tries to pass information to other teachers regarding students, but information passed was not accurate.

Moreover, students face academic difficulty in the learning material. When students do not grasp the lessons taught they feel frustrated and school adjustment is obstructed.

I feel sad in class, because I do not understand what the teacher tries to explain.

Despite the long experience of some teachers, they do not have an easy and clear method in introducing the learning material. Students feel sad because they cannot comprehend lessons explained in a complicated way.

The problem we have in class is that although there are teachers who have long teaching experience but their way in teaching is obscure...we can't understand

The science teacher's voice is so low, and we keep on asking her to speak up but it's no use, I face difficulties in concentrating because most of the time I can't hear the teacher in the class

Some students complain that they cannot understand the lesson because they feel very embarrassed by the negative comments from teachers themselves as well as from classmates.

I always ask when I don't understand anything. Good teachers repeat whatever part of the lesson that I don't understand and answer all my questions. Some comments from classmates such as "dummy" or "teacher, you need to repeat the lesson 20 times for him to understand" make me hesitate to ask further questions, and that's why I don't understand the lesson anymore

Some teachers become angry when we ask questions. They want to go on with the lesson to complete the requirements on time, "you have to concentrate to understand" and that's why I don't ask questions anymore

The real reason for not understanding during lessons is not only because of the student's attitude towards the material, but also his/her attitude towards the teacher (instructor). Students have feelings of stress and fear as soon as they see the teacher.

Well, when I see my teacher, I get sort of a feeling in my stomach and my hands get all sweaty. Even my heart starts to pound

Despite feelings of stress for not being able to communicate with the teacher in the classroom, family plays an important role in developing sadness. Students face tremendous stress from their parents expecting them to get high grades. School grades are considered the only way to evaluate the students' performance in Jordanian schools. As a result, getting a low grade or even an average grade indicates that the student is careless.

Dad always tells me that I'm smart and I have to get the highest grade. He always encourages me but the problem is that I can't convince him, that I'm just like my school mates and can't be the best among the students, not because I do not want to, but because there are students who are more brilliant.

Describing school as the major factor in feeling depressed and sad is related to not understanding lessons explained in class. Students do not pay attention to the teacher and turn to unaccepted behaviour such as drawing on books or writing on the walls or even distracting other students.

When I don't understand what the teacher is saying, I spend my time drawing and writing, I sometimes tease my friends in order to make the teacher kick me out of class, and I get bored because all the students pay attention to the teacher except me

\subsubsection{Peer Influences}

Peer influence is a way to describe how children's behaviour is shaped by wanting to feel they belong to a group of friends or peers. Peer influence is doing something you wouldn't do, because you want to feel accepted and valued by your friends. It is doing something against your will.

Sometimes I enforced to do something I don't want to do it but because of my friend.

Sometimes I feel bad to do things against my beliefs. 
Peer influence can be positive, child might be influenced to become more assertive, try new activities, or to get more involved with school. But it can be negative too. Some children might choose to try things they normally wouldn't be interested in, such as antisocial behaviour.

I always try to choose the same clothes, hairstyle or jewellery as my friends.

I usually listen to the same music or watching the same TV shows as my friends.

I enjoy some times to do risky things or breaking rules at my schools as my friends did.

As a result of peer influence, school that host bullying and peer victimization contribute to develop depressive feelings, children who are bullied develop negative attitudes about school and tend to view school as less supportive than other students view it.

Being a frequent target of bullying is associated with peer rejection, low self-esteem, depression, and insecurity.

I hate my school and I hate my friends everyone in school hit me and they treat me in a bad way every time

The experience of bullying may lead to life-threatening consequences for some children. Some children have found a connection between bully victimization and suicidal thoughts

Because of the bad way I treated from my peer in the school I want to kill myself

Peer contagion processes significantly contribute to internalizing symptoms as mention from interviewed children.

More time I spend observing, hearing, and sharing depressing stories from my peer, I experience negative mood and I feel sad and become more miserable at the rest of the day

\section{Discussion}

Information about the prevalence of childhood depression is essential for planning mental health care and developing strategies for intervention. The increasing incidence rates of psychiatric disorders have drawn attention of the scientific world to mental health research. The World Health Organization (WHO) estimates that, until the year 2021, depression will be the second largest cause of the global disease. However, cases of depressive disorders have increased not only among adults, but also among children, 4-6 with a prevalence of $0.3 \%$ to $7.8 \%$ in children below 13 years old.

Research has found that the first symptoms of major depression emerge around age 11-12, and that less severe symptoms can be observed in children as young as 7-8 (Del Barrio, 2000; Kovacs, et al., 1984).

This study provides data showing that in the current sample of 13-year-old children about $6.8 \%$ might be expected to meet the criteria for major depressive symptoms. In previous studies, prevalence of depression ranged between 1-2\% and rates differ little between boys and girls (Egger \& Angold, 2006) Levels then begin to rise in the early teens, more sharply in girls than boys with prevalence rate of 4-5\% (Maughan et al., 2003). As regards possible differences by sex, various studies have found greater prevalence of depressive symptoms in boys than in girls aged between 6 and 12, the prevalence of depressive symptoms tends to be higher in girls, reaching a ratio of as much as 2:1 with respect to boys (Angold, et al., 2002; Del Barrio, et al., 1997).

Moreover, the results reported by Mathet et al., 2003 indicated that more than $10 \%$ children aged less than 13 years had a depressive symptoms. The findings in this study suggest that the view of the prevalence of childhood depression in the current sample is relatively higher. Differences in methods of diagnosing childhood depression in conjunction with differences in sample size may account for some of the discrepancy in rates. On the other hand, according to my viewpoint, the situation of children and people in Jordan is not like other countries, because Jordan has a sensitive position between the countries of the Middle East that made it under the influences of many political, economic and social changes. This influence of different types was not limited to a specific aspect, but it involved all different aspects of life. For example, concerning the politics, Jordan, as mentioned previously was under the influence of many wars of struggles, which had a big influence on the psychological aspect of the entire Jordanian population. As a result of the political situation, Jordan was faced with a massive influx of refugees, who had a profound impact on the economic situation of our people. This increase of the population put immense pressure on all our services, particularly health and education, and affected the quality of life across all sectors of Jordanian society

The school environment is likely to be implicated in the development of depression. This view is corroborated, at least partially, by the fact that certain forms of psychological distress, including depressive symptoms, increase during the school years. Perceptions of being academically competent and receiving good grades have been linked with a reduced risk for emotional and behavioural difficulties; whereas low perceived academic 
competence is related to depressive symptoms in children (Cicchetti \& Toth, 1998). In general, it has become clear that problems of academic alienation, poor school performance, and delinquency which have become more prominent in children are linked to negative mental health problems such as depression that are manifested later in adolescence (Chen et al., 1995). However, inappropriate school environments during childhood can place many young people at risk of a depression. Furthermore, teachers in the schools evaluate children's school performance in both the social and academic areas, but how do Jordanian children evaluated their relationships with teachers? According to the children the first problem that faced them is the physical punishment of a child by the teachers, which might mean both common minor physical discipline as well as cases of physical abuse of children by teachers. This was proved as the strongest predictor for a child's depression. This finding stresses the peril of the aggressive attitude of teachers as related to the mental health of the child, and the authorities should direct attention to new forms of teacher training in order to prevent the unfavourable consequences to the psychological development of children.

Primary goal for a child in school is to develop social competencies such as making friends. According to my experience in the Jordanian school, one of the most common complaints I hear from children is that they do not have any friends. Depressed and lonely children magnify their isolation and often feel like everybody is watching them; these feelings obviously lead to more withdrawal and depression. According to the interviewed children, peer influence such as the lack of friends may develop depression. In particular, important emotional responses often have not been developed. Also these children may be overly affected by common jokes or talk among peers due to over- personalisation; they feel like they are not part of group.

\section{References}

Aktepe, E., Demirci, K., Calıskan, A. M., \& Sonmez, Y. (2010). Symptoms and diagnoses of patients referring to a child and adolescent psychiatry polyclinic. Dusunen Adam. The Journal of Psychiatry and Neurological Sciences, 23, 100-108.

Allgaier, A., Krick, K., Opitz, A., Saravo, B., Romanos, M., \& Schulte-Körne, G. (2014). Improving early detection of childhood depression in mental health care: The Children's Depression Screener (ChilD-S). Psychiatry Res., 217, 248-252.

American Psychiatric Association, APA. (2000). Diagnostic and Statistical Manual of Mental Disorders (4th ed.). Text Revision. Washington, DC: American Psychiatric Association.

Angold, A., Erkanli, A., Silberg, J., Eaves, L., \& Costello, E. J. (2002). Depression scale scores in 8-17-year-olds: Effects of age and gender. Journal of Child Psychology and Psychiatry, 43,1052-63.

Bilac, O., Ercan, E. S., Uysal, T., \& Aydın, C. (2014). Prevalence of Anxiety and Mood Disorders and Demographic Characteristics of Elementary School Students. Turk Psikiyatri Derg, 25, 171-180.

Birmaher, B., Arbelaez, C., \& Brent, D. (2002). Course and outcome of child and adolescent major depressive disorder. Child and Adolescent Psychiatric Clinics of North America, 11, 619-637.

Bruns, E. J., Walrath, C., Glass-Siegel, M., \& Weist, M. D. (2004). School-based mental health services in Baltimore: Association with school climate and special education referrals. Behavior Modification, 28(4), $491-512$

Chen, X., Rubin, K., \& Li, B. (1995). Depressed mood in Chinese children: Relations with school performance and family environment. Journal of Consulting and Clinical Psychology, 63(6), 938-947.

Cicchetti, D., \& Toth, S. L. (1998). The Development of Depression in Children and Adolescents. American Psychologist, 53, 221-241.

Comer, R. (2010). Abnormal psychology. New York: Worth publishers.

Corona, M., McCarty, C., Causce, A., Robins, R., Widaman, K., \& Conger, R. (2012). The Relation between Maternal and Child Depression in Mexican American Families. Hispanic Journal Sciences, 34(4), 539-556.

Defilipis, M., \& Wanger, K. D. (2014). Management of treatment-resistant depression in children and adolescents. Paediatr Drugs, 16(5), 353-61.

Del Barrio, V., Moreno, C., \& López, R. (1998). Ecology of depression in Spanish children. European Psychologist, 2, 18-27.

Doerfler, L., Felner, R., Rowlison, R., Raley, P., \& Evans, E. (1988). Depression in children and adolescents: A comparative analysis of the utility and construct validity of two assessment measures. Journal of Consulting and Clinical Psychology, 56(5), 769-772. 
Egger, H. L., \& Angold, A. (2006). Common emotional and behavioural disorders in preschool children: Presentation, nosology, and epidemiology. J. Child. Psychol. Psychiatry, 47, 313-337.

Greenberg, M. T., Domitrovich, C., \& Bumbarger, B. (2001). The prevention of mental disorders in school-aged children: Current state of the field [Electron version]. Prevention and Treatment, 4.

Hammen, C., \& Rudolph, K. D. (1996). Childhood depression. In E. J. Mash \& R. A. Barkley (Eds.), Child psychopathology (pp. 153-195). New York: Guilford Press.

Haugaard, J. (2008). Child psychopathology. Boston: McGraw-Hill.

Herman, K. C., \& Ostrander, R. (2007). The effects of attention problems on depression: Developmental, academic, and cognitive pathways. School Psychology Quarterly, 22, 483 - 510.

Kasen, S., Johnson, J., \& Cohen, P. (1990). The impact of school emotional climate on student psychopathology. Journal of Abnormal Child Psychology, 18, 165 - 177.

Kaye, D., Montgomery, M., \& Munson, S. (2002). Child and adolescent metal health. Philadelphia: Lippincott Williams \& Wilkins.

Kazdin, A. (1989). Identifying depression in children: a comparison of alternative selection criteria. Journal of Abnormal Child Psychology, 17(4), 437-454.

Kendall, P. (2000). Childhood Disorders. UK:Psychology Press Ltd.

Khoury-Kassabri, M., Benbenishty, R., \& Avi Astor, R. (2005). The effects of school climate, socioeconomics, and cultural factors on student victimization in Israel. Social Work Research, 29(3), 165-180.

Knitzer, J., Steinberg, Z., \& Fleisch, B. (1991). Schools, children's mental health, and the advocacy challenge. Journal of Clinical Child Psychology, 20(1), 102-111.

Kovacs, M. (1992). Children's Depresssion Inventory: New Depression Inventory. New York: Multi-Health Systems.

Kovacs, M., Feinberg, T., Crouse-Novak, M., Paulauskas, S., \& Filkenstein, R. (1984). Depressive disorders in childhood: I. a longitudinal perspective study of characteristics and recovery. Archives of General Psychiatry, 41, 229-237.

Kring, A., Johnson, S., Davison, G., \& Neale, J. (2010). Abnormal psychology. New York: John Wiley \& Sons, Inc.

Kuperminc, G. P., Leadbeater, B. J., \& Blatt, S. J. (2001). School social climate and individual differences in vulnerability to psychopathology among middle school students. Journal of School Psychology, 39, 141-159.

Lima, N. N., do Nascimento, V. B., de Carvalho, S. M., de Abreu, L. C., Neto, M. L., Brasil, A. Q., Junior, F. T., de Oliveira, G. F., \& Reis, A. O. (2013). Childhood depression: A systematic review. Neuropsychiatr Dis Treat, 9, 1417-1425.

Lin, J., Tung, H., Hsieh, Y., \& Lin, F. (2011). Interactive Effects of Delayed Bedtime and Family-Associated Factors on Depression in Elementary School Children. Research in Developmental Disabilities. Multidisciplinary Journal, 32(6), 2036-2044.

Liu, X. C., Kurita, H., Guo, C., Miyake, Y., Ze, J., \& Cao, H., (1999). Prevalence and risk factors of behavioral and emotional problems among Chinese children aged 6 through 11 years. Journal of the American Academy of Child and Adolescent Psychiatry, 38, 708-715.

Loeber, R., Green, S. M., \& Lahey, B. B. (1990). Mental health professionals' perception of the utility of children, mothers, and teachers as informants on childhood psychopathology. Journal of Clinical Child Psychology, $19,136-143$.

Loukas, A., \& Robinson, S. (2004). Examining the moderating role of perceived school climate in early adolescent adjustment. Journal of Research on Adolescence, 14(2), 209-233.

Loukas, A., Suzuki, R., \& Horton, K. D. (2004). Examining school connectedness as a mediator of school climate effects. Journal of Research on Adolescence, 16(3), 491-502.

Mathet, F, Martin, G. C., Maurice, T., S., \& Bouvard, M. P. (2003). Prevalence of depressive disorder in children and adolescents attending primary care. A survey with the Aquitaine Sentinelle Network. Encephale, 29, 391-400. 
Maughan, B., Rowe, R., Loeber, R., \& Stouthamer-Loeber, M. (2003). Reading problems and depressed mood. Journal of Abnormal Child Psychology, 31, 219-229.

Mehler-Wex, C., \& Kölch, M. (2008). Depression in children and adolescents. Dtsch. Arztebl. Int., 105, 149-155.

Miller, J. (1998). The childhood depression source book. Los Angeles: Contemporary Publishing Group.

Nelson, R. (2001). Introduction to counselling skills. London: Sage Publications Ltd.

Nevid, J., Rathus, S., \& Greene, B. (2006). Abnormal psychology. Upper Saddle River: Prentice Hall.

Reynolds, C. R., \& Kamphaus, R. W. (2004). Behavior assessment system for children (2nd ed.). Circle Pines, $\mathrm{MN}$ : American Guidance Service

Roeser, R. W., Van der Wolf, K., \& Strobel, K. R. (2001). On the relation between social-emotional and school functioning during early adolescence. Preliminary findings from Dutch and American samples. Journal of School Psychology, 39, 111-139.

Saqib, T. (2014). Maternal Depression: A Risk Factor of Childhood Mental Illness. Journal of Social Sciences, $8(1), 24-30$

Sarason, S. (2007). Abnormal psychology: the problem of maladaptive behaviour. Academic internet publishers: U.S.A.

Steinhausen, H. C., \& Winkler Metzke, C. (2003). Prevalence of affective disorders in children and adolescents: Findings from the Zurich Epidemiological Studies. Acta Psychiatrica Scandinavica Supplementum, 418, $20-23$.

Thapar, A., Collishaw, S., Pine, D. S., \& Thapar, A. K. (2012). Depression in adolescence. Lancet, 379(9820), 1056-1067.

Uusitalo-Malmivaara, L., \& Lehto, J. (2013). Social Factors Explaining Children's Subjective Happiness and Depressive Symptoms. Social Indicators Research, 111(2), 603-615.

Wang, L., Feng, Z., Yang, G., Yang, Y., Dai, Q., Hu, C., Liu, K., Guang, Y., Zhang, R., Xia, F., \& Zhao, M. (2015). The epidemiological characteristics of depressive symptoms in the left-behind children and adolescents of Chongqing in China. J. Affect Disorder, 13, 36-41.

Williamson, D. E., Birmaher, B., Dahl, R. E., \& Ryan, N. D. (2005). Stressful life events in anxious and depressed children. J. Child Adolesc. Psychopharmacol, 15(4), 571-580.

Woo, B. S. C., Ng, T. P., Fung, D. S. S., Chan, Y. H., Lee, Y. P., Koh, J. B. K., \& Cai, Y. (2007). Emotional and behavioural problems in Singaporean children based on parent, teacher and child reports. Singapore Medical Journal, 48, 1100-1106.

World Health Organization. The world health report 2011 - Men-tal Health: New Understanding, New Hope. Geneva: World Health Organization; 2001.

Yap, M. B. H., \& Jorm, A. F. (2015). Parental factors associated with childhood anxiety, depression, and internalizing problems: a systematic review and meta-analysis. J. Affect. Disord., C 175, 424-440.

\section{Copyrights}

Copyright for this article is retained by the author(s), with first publication rights granted to the journal.

This is an open-access article distributed under the terms and conditions of the Creative Commons Attribution license (http://creativecommons.org/licenses/by/4.0/). 